\title{
Implantação de uma unidade de prevenção e tratamento para úlcera de perna falciforme: uma proposta para assistência de enfermagem
}

\author{
Deployment of a unit for ulcer prevention and treatment of sickle cell leg: a proposal for \\ nursing care
}

\author{
Implantación de una unidad de prevención y tratamiento de la úlcera falciforme: una \\ propuesta de cuidados de enfermería
}

Iraildes Alves De Moura Gomes ${ }^{1 *}$, Bruna Furtado Sena de Queiroz².

\begin{abstract}
RESUMO
Objetivos: Verificar na literatura como ocorre o funcionamento de uma Unidade de Prevenção e Tratamento de úlceras de perna falciforme em um hemocentro. Revisão bibliográfica: Tradicionalmente, o principal tratamento da úlcera de perna falciforme continua a ser uma combinação de higiene local para evitar inflamação e infecção, a elevação da perna, e repouso prolongado, que geralmente não é viável; além destas, existem outras formas de tratamento baseadas nas terapias tópicas e sistêmicas, tais como curativos em gel, antibióticos tópicos, suplementação com zinco, enxertos de pele e transfusões sanguíneas. O estudo demonstrou os caminhos necessários para a construção de uma Unidade de Tratamento e Prevenção de Úlceras Falciformes, identificou a condução terapêutica dos casos e o levantamento bibliográfico sobre as abordagens e conduções das úlceras de perna falciforme, assim como as medidas preventivas e sua aplicação. Considerações finais: Cuidar de uma pessoa com feridas requer dos profissionais responsáveis pela assistência, onde é necessário um leque de possibilidades terapêuticas visando auxiliar na condução destes casos, bem como melhorar a qualidade da assistência oferecida. Sendo assim, cabe aos enfermeiros intervir de forma consensual na escolha adequada do tratamento das úlceras falciforme.
\end{abstract}

Palavras-chave: Anemia falciforme, Úlcera da perna, Úlcera, Enfermagem.

\begin{abstract}
Objectives: To verify in the literature how a sickle leg ulcers Prevention and Treatment Unit works in a blood center. Bibliographic review: Traditionally, the main treatment for sickle leg ulcer remains a combination of local hygiene to prevent inflammation and infection, leg elevation, and prolonged rest, which is generally not feasible; in addition to these, there are other forms of treatment based on topical and systemic therapies, such as gel dressings, topical antibiotics, zinc supplementation, skin grafts and blood transfusions. The study demonstrated the necessary paths for the construction of a Sickle Cell Ulcer Treatment and Prevention Unit, identified the therapeutic management of cases and the bibliographic survey on the approaches and management of sickle leg ulcers, as well as preventive measures and their application. Final considerations: Taking care of a person with wounds requires professionals responsible for care, where a range of therapeutic possibilities is needed to help manage these cases, as well as improve the quality of care provided. Therefore, it is up to nurses to intervene consensually in the proper choice of treatment for sickle cell ulcers.
\end{abstract}

Keywords: Sickle cell anemia, Leg ulcer, Ulcer, Nursing.

\section{RESUMEN}

Objetivos: Verificar en la bibliografía cómo funciona una Unidad de Prevención y Tratamiento de las úlceras falciformes en un centro de sangre Revisión bibliográfica: Tradicionalmente, el tratamiento principal para la úlcera falciforme de la pierna sigue siendo una combinación de higiene local para prevenir la inflamación y la infección, la elevación de la pierna y el descanso prolongado, que generalmente no es factible; Además de estos, existen otras formas de tratamiento basadas en terapias tópicas y sistémicas, como apósitos en gel, antibióticos tópicos, suplementación con zinc, injertos de piel y transfusiones de sangre. El estudio demostró los caminos necesarios para la construcción de una Unidad de Tratamiento y Prevención de la Drepanocitosis, identificó el manejo terapéutico de los casos y el relevamiento bibliográfico sobre los abordajes y manejo de drepanocitosis, así como las medidas preventivas y su aplicación. Consideraciones finales: El cuidado de una persona con heridas requiere de profesionales responsables del cuidado, donde se necesita un abanico de posibilidades terapéuticas que ayuden a manejar estos casos, así como a mejorar la calidad de la atención brindada. Por lo tanto, corresponde a las enfermeras intervenir de manera consensuada en la elección adecuada del tratamiento para las úlceras falciformes.

Palabras clave: Anemia falciforme, Úlcera de pierna, Úlcera, Enfermería.

${ }^{1}$ Universidade Estadual do Piauí (UESPI), Teresina - PI. *E-mail: iraildesalves@gmail.com

2 Universidade Federal do Piauí (UFPI), Teresina - PI. 


\section{INTRODUÇÃO}

Doença falciforme (DF) é o termo utilizado para referir a síndromes provocadas pela presença de moléculas de hemoglobinas geneticamente modificadas (denominada hemoglobina $S$ ) na corrente sanguínea. De acordo com dados demográficos, a DF pode ser considerada a doença hereditária mais prevalente no mundo. No Brasil, estima-se que nascem 3000 crianças por ano com a doença (CAVALCANTE IM e MAIO MC, 2011; NEVES AF, et al., 2010; FERNANDES AP, et al., 2010).

O tratamento da DF tem como indicação a correção da anemia crônica, prevenção de complicações, terapia transfusional e/ou exsanguineotransfusão (BRASIL, 2005). Portanto, por ser uma doença crônica, o acompanhamento regular em centros especializados realizado por profissionais capacitados seguindo protocolos clínicos, com acesso a recursos diagnósticos e terapêuticos, a educação dos pacientes sobre a doença e, o estímulo ao autocuidado são indispensáveis para a redução da morbimortalidade por DF (RAMALHO AS e MAGNA LA, 2007). Uma das complicações da doença é a úlcera de perna em associação com a DF. Este tipo de complicação. "O primeiro paciente com DF a ser descrito na América do Norte em 1910 teve ulcerações crônicas de perna" (BRASIL, 2005).

As úlceras de perna estão entre as mais evidentes manifestações cutâneas da anemia falciforme devido a sua elevada frequência, cronicidade e resistência à terapia disponível, com elevadas taxas de recorrência, podendo ser de início espontâneo ou traumático. Geralmente surgem na região maleolar medial e lateral, mais raramente na região pré - tibial e dorso do pé (PALADINO SF, 2007).

Embora quase $80 \%$ dos pacientes com úlceras de perna associadas a DF consigam se curar, em alguns, as úlceras podem persistem por vários anos ou até mesmo nunca cicatrizar, sendo que depois da cura podem ocorrer recidivas. Esse tipo de ferida tem evolução crônica, são resistentes e causam problemas de ordem física, psicológica e social. A dor, nestes casos, pode ser severa, aguda e na forma de ardência. Outra questão a ser considerada são os custos gerados com a assistência à saúde no tratamento deste tipo de lesão que, dado as suas características, pode ser bem elevado (SPIRA JAO, et al., 2020).

As úlceras, temporárias ou permanentes, ocasionam problemas que, além de cuidados contínuos, necessitam também de acompanhamento multidisciplinar, mudança de comportamento e adesão ao tratamento (SPIRA JAO, et al., 2020). Nesta perspectiva, o conhecimento acerca dos processos fisiológicos que envolvem a cicatrização de feridas auxilia o enfermeiro e demais profissionais envolvidos na assistência a reconhecer a fase em que se encontra e permite identificação de ocorrências para eleger medidas capazes de facilitar o processo e impedir complicações, além de fundamentar a escolha dos produtos adequados a cada fase (LOBO C, et al., 2007).

Nesse sentido, a busca por estratégias e ações que aproximem a atenção em saúde das necessidades desses usuários falcêmicos e ulcerados é urgente, propiciando o seguinte questionamento: como pode ser implantada uma Unidade de Prevenção e Tratamento de úlcera de perna falciforme em um hemocentro?Tem-se como objetivo geral desta pesquisa verificar na literatura quais os requisitos e como ocorre o funcionamento de uma Unidade de Prevenção e Tratamento de úlceras de perna falciforme em um hemocentro.

\section{REVISÃO BIBLIOGRÁFICA}

Entre os requisitos necessários para a construção de uma Unidade de Tratamento e Prevenção de Úlceras Falciformes em um hemocentro pode-se identificar 3, durante a revisão, de forma resumida: construção da estrutura da Unidade provida com insumos adequados; conhecimento das formas de abordagem e condutas possíveis durante o tratamento desse tipo de ferida; e, conhecimento e aplicação de medidas preventivas.

\section{Construção da unidade}

No Quadro 1 abaixo, apresentamos uma proposta dos itens necessários para a construção da unidade de tratamento e prevenção de úlceras falciformes. Já a Figura 1 ilustra um modelo de cartão de aprazamento. 
Quadro 1 - Itens necessários para construção de uma Unidade de Tratamento de Úlceras Falciformes.

\begin{tabular}{|c|c|}
\hline Item Necessário & Descrição \\
\hline $\begin{array}{l}\text { Espaço físico } \\
\text { adequado }\end{array}$ & $\begin{array}{l}01 \text { sala para acolhimento de pacientes e familiares; } \\
01 \text { sala para realização de palestras educativas tanto para pacientes como } \\
\text { para familiares; } \\
01 \text { sala para atendimento individual contendo mesa com cadeira, maca, um } \\
\text { armário para material de curativo e medicações, lavabo, lixeira comum e } \\
\text { local de descarte paraperfuro-cortante. }\end{array}$ \\
\hline Material de apoio & $\begin{array}{l}\text { Material educativo impresso; } \\
\text { Cartão de aprazamento. }\end{array}$ \\
\hline Banco de dados & Registro dos pacientes com todos os dados clínicos e hematológicos \\
\hline $\begin{array}{l}\text { Protocolo de } \\
\text { acompanhamento }\end{array}$ & $\begin{array}{l}\text { Protocolo para acompanhamentos dos casos (identificação do paciente, } \\
\text { endereço, diagnóstico, avaliação clínica, espaço para registro de condutas } \\
\text { e/ou caracteristicas da lesão, tipo de curativo, suporte necessário e evolução } \\
\text { do caso) }\end{array}$ \\
\hline $\begin{array}{l}\text { Profissionais } \\
\text { treinados }\end{array}$ & $\begin{array}{l}\text { A equipe de profissionais deve ser treinada para assistir a esses pacientes de } \\
\text { forma adequada considerando suas particularidades e o protocolo de } \\
\text { atendimento instituido na unidade }\end{array}$ \\
\hline
\end{tabular}

Fonte: Gomes IAM e Queiroz BFS, 2021.

Figura 1 - Modelo de cartão de aprazamento.

MODELO DO CARTÃO DE APRAZAMENTO DE RETORNO

Frente do Cartão

\begin{tabular}{|c|c|c|c|c|}
\hline \multicolumn{5}{|c|}{ Unidade de Prevenção e Tratamento de Ulcera Falciforme } \\
\hline \multicolumn{3}{|c|}{ Nome do paciente: } & \multicolumn{2}{|c|}{ Telefone } \\
\hline \multicolumn{3}{|l|}{ Prontuário: } & & \\
\hline \multicolumn{5}{|c|}{ AGENDA E PROGRAMAÇAO DAS PALESTRAS } \\
\hline SEGUNDA & TERÇA & QUARTA & QUINTA & SEXTA \\
\hline $\begin{array}{c}\text { Doença } \\
\text { Falciforme } \\
\text { Depoimentos }\end{array}$ & $\begin{array}{c}\text { Ulceras } \\
\text { Depoimentos }\end{array}$ & $\begin{array}{l}\text { Prevenção } \\
\text { Promoção } \\
\text { Depoimentos }\end{array}$ & $\begin{array}{l}\text { Complicações } \\
\text { Tratamento } \\
\text { Depoimentos }\end{array}$ & Atividade lúdica \\
\hline
\end{tabular}

\begin{tabular}{|l|l|l|}
\hline Data do atendimento atual & \multicolumn{1}{|c|}{ Data do Retorno } & Horário \\
\hline & & \\
\hline & & \\
\hline & & \\
\hline & & \\
\hline & & \\
\hline & & \\
\hline & & \\
\hline & & \\
\hline
\end{tabular}

Fonte: Gomes IAM e Queiroz BFS, 2021. 


\section{Abordagens e condutas possíveis durante o tratamento}

Tradicionalmente, o principal tratamento da úlcera de perna falciforme continua a ser uma combinação de higiene local para evitar inflamação e infecção, a elevação da perna, e repouso prolongado, que geralmente não é viável. Além destas, Martins A (2013) ressaltam outras formas de tratamento baseadas nas terapias tópicas e sistêmicas, tais como curativos em gel, antibióticos tópicos, suplementação com zinco, enxertos de pele e transfusões sanguíneas.

Nesta perspectiva, Naoum FA (2010) ressalta que as úlceras de perna falciforme são difíceis de curar e podem ter longa duração onde o gerenciamento da dor torna-se uma questão importante para esta complicação. Pensando na questão da dor, Palatino SF (2007) desenvolveu uma pesquisa por meio do acompanhamento de 500 voluntários que realizavam diariamente curativos em uma Unidade Hospitalar e constataram que alguns pacientes podem obter controle da dor apenas com altas doses de opióide oral ou parenteral em uma base diária. No entanto, estes autores chamam atenção para os possíveis efeitos colaterais, a baixa qualidade de vida e o potencial viciante da medicação.

Dias ALAA (2013) identificaram que a analgesia com opióides tópicos é uma ideia interessante que pode vir a dar grande alívio da dor sem causar problemas de saúde significativos, uma vez que seu mecanismo envolve a ação local da morfina sobre os receptores opióides do nervo periférico e úlceras de perna. Já Trent JT (2004) identificou que a câmara hiperbárica de oxigenoterapiaprecipita a dor severa do paciente e transfusão crônica que leva à sobrecarga de ferro, ou seja, não é indicada para o tratamento de úlceras de perna falciforme. No entanto, a arginina butirato no tratamento, teve bons resultados.

Outra terapia sugerida, porém, que ainda permanece em controvérsia, trata-se da Hidroxiureia (HU). Esta terapia age aumentando a média de $\mathrm{Hb}$ fetal e $\mathrm{Hb}$, que por sua vez auxilia a cicatrização da úlcera. Segundo Nolan VG, et al. (2006) as transfusões sanguíneas também podem ser preconizadas para a terapia de úlceras de perna falciforme, com o objetivo de aumentar a capacidade de transporte de oxigênio do sangue, elevando a concentração de $\mathrm{Hb}$, diluindo a $\mathrm{Hb} \mathrm{S}$. No entanto, podem acontecer algumas complicações associadas à transfusão, tais como: sobrecarga de ferro e aloimunização.

Palatino SF (2007) identificou que as úlceras de perna falciforme têm fortes semelhanças com úlceras vasculares crônicas na população em geral, no que diz respeito à presença de alto fluxo sanguíneo, vasos sanguíneos anormais e inflamação crônica. Um experimento controlado de terapia oral com sulfato de zinco em pacientes com anemia falciforme mostrou melhora em úlceras de perna (NOLAN VG, et al., 2006).

Halabi TM, et al. (2008) identificaram em sua pesquisa que a compressão física, como a bota de Unna ou meias de compressão é indicada em outros tipos de úlcera cutânea, apontaram o uso ocasional de enxertos de pele e colágeno com desbridamento cirúrgico, como estratégias de tratamento em úlceras de perna falciforme baseados em evidências.

Outra terapia sugerida, porém, que ainda permanece em controvérsia, trata-se da Hidroxiureia (HU). Esta terapia age aumentando a média de hemoglobina $(\mathrm{Hb})$ fetal e $\mathrm{Hb}$, que por sua vez auxilia a cicatrização da úlcera. Halabi TM, et al. (2008) também concordam com esses achados e acrescentam que a hidroxiuréia melhora a defesa antioxidante em pacientes com anemia falciforme e contribui para uma maior atividade da catalase e trolox.

Por outro lado, em uma pesquisa realizada por Dumville JC, et al. (2009) há relatos de formação de úlcera após utilização da $\mathrm{HU}$ e também indícios de piora das úlceras de perna em alguns pacientes com doença falciforme. Segundo Palatino SF (2007) as transfusões sanguíneas também podem ser preconizadas para a terapia de úlceras de perna falciforme, com o objetivo de aumentar a capacidade de transporte de oxigênio do sangue, elevando a concentração de $\mathrm{Hb}$, diluindo a $\mathrm{Hb} \mathrm{S}$.

No entanto, podem acontecer algumas complicações associadas à transfusão, tais como: sobrecarga de ferro e aloimunização. Dumville JC, et al. (2009) citam também o laser de baixa intensidade (LBI), pois sua pesquisa identificou que é um método eficaz para a modulação da reparação tecidual, contribuindo significativamente para um rápido e melhor processo de cicatrização. 
Com relação a dor causada por este tipo de úlcera devemos considerar que esta é presente de forma constante, piora durante os curativos, causa perda da mobilidade e independência impactando diretamente na qualidade de vida. Portanto, algumas terapias de analgesia foram sugeridas para proporcionar maior conforto ao paciente como, por exemplo: uso de pomadas ou outros tipos de analgesia tópica antes da realização dos curativos; e, o uso de opioides por via oral ou parenteral na rotina diária atentando para os possíveis efeitos colaterais e o potencial viciante deste tipo de medicação (PALADINO SF, 2007; NAOUM FA, 2010; NEVES AF et al., 2010); MARTINS A, 2013).

Foi possível observar que apesar dos inúmeros métodos terapêuticos citadas nas pesquisas analisadas para o tratamento dos casos de úlceras de perna falciforme, houve um consenso em afirmar que a escolha adequada do tratamento e o esforço da equipe médica e de enfermagem podem fazer com que o processo de cicatrização seja mais rápido e reduzir possíveis complicações desta enfermidade (NAOUM FA, 2010).

\section{Medidas Preventivas e suas Aplicações}

Assim como no tratamento, para a prevenção de úlceras é de suma importância a promoção do conhecimento sobre práticas, cuidados e fatores que podem melhorar ou piorar a saúde desses pacientes tanto para eles mesmos como para a família, levando sempre em consideração as suas particularidades: fatores biológicos, sociais e educacionais. Palastino SF (2007) recomendam que, para a prevenção das consequências a exemplo da úlcera de perna falciforme, o tratamento deve ser iniciado o mais precocemente possível.

Araújo PIC (2007) afirma que a educação em saúde no tratamento e prevenção de úlceras secundárias à Doença Falciforme, deve priorizar a hidratação da pele, com hidratantes naturais ou cosmetológicos. Os pacientes devem ser orientados sistematicamente, sobre a inspeção da pele, principalmente das pernas nas regiões maleolares, para detectar possíveis portas de entrada para úlceras de pernas.

Também devem ser orientados para evitar coçar os membros inferiores após picadas de insetos e a usar repelentes e inseticidas para diminuir a possibilidade dessa ocorrência. Outra forma de prevenir é o uso sistemático de calçados e de meias de algodão macias. Martins A, et al. (2013) esclarecem que, quando houver a presença de edema ou úlceras prévias, deve-se orientar o uso de meias elásticas acima dos joelhos.

Os pacientes devem receber orientação sobre a doença e suas complicações, além de ser disciplinados quanto à importância de manter uma hidratação e nutrição adequadas e de ficarem alerta ao sinal de palidez. A prevenção de infecções e a atualização do estado vacinal devem ser encorajadas e monitoradas pelos profissionais de saúde (MARTINS A, 2013).

Segundo Junqueira PC, et al. (2009) o aconselhamento genético possui primordialmente caráter assistencial, educativo e preventivo, permitindo aos doentes e às suas famílias: compreenderem o diagnóstico, a causa e a evolução da doença e as condutas disponíveis; assimilar como a hereditariedade contribui para determinada doença e o risco de recorrência; escolher a conduta mais apropriada em frente à procriação, respeitando a autonomia e seus padrões éticos e religiosos.

Veríssimo MPA (2007) acrescentam ainda que a estratégia de Promoção da saúde em DF deve articular de forma transversal e visível todos os aspectos que colocam a vida em risco, as distinções entre as necessidades, as regiões e as culturas deste grupo de pessoas. Para atingir esse objetivo, devemos utilizar táticas como estimar os riscos e as vulnerabilidades expostas a determinados sujeitos.

O risco se explica pela possibilidade de acontecer determinado evento. A gestão analítica do risco permite identificar o intervalo de probabilidades de um uma população apresentar um agravo, transformando-se em empenho na investigação de controle das ameaças à saúde, direcionando metas, reorientando modelos de ação, relacionando-se diretamente com a promoção em saúde (JUNQUEIRA PC, et al., 2009).

A identificação dos riscos, indicador de possibilidades e vulnerabilidades, indicador da iniquidade e da desigualdade social, do portador de úlcera falciforme é uma busca proposital da síntese dos elementos 
concretos e abstratos associados e associáveis à injúria, calçando a elaboração de projetos de sólida mudança nas práticas em saúde, nas quais o cuidado assume caráter efetivo e relevante (MARTINS A, et al., 2014).

Assim, pode-se incluir nessa força tarefa o aceso ampliado a uma alimentação saudável e de melhor qualidade nutricional respeitando as restrições ou necessidade da doença, existência de redes de suporte social, ferramentas de mediação de conflitos, inibição do alcoolismo e tabagismo e as demais que possam ressarcir os fatores comportamentais, socioeconômico, culturais e ambientais que possam interferir direta ou indiretamente no aparecimento da úlcera (KIKUCHI BA, 2007).

Segundo Martins A (2013) a eficácia e eficiência dos planos preventivos dependem principalmente do papel do usuário, quando ele deixa de ser passivo e passa a se o agente do processo. A prevenção como estratégia de ação para a úlcera deve focar que o estilo de vida e comportamento do indivíduo são fatores determinantes e eles e podem prevenir, iniciar ou agravar o problema. Segundo Junqueira PC, et al. (2009) as ações preventivas devem ser conduzidas em dois espectros, os fatores de riscos não modificáveis (sexo, idade, herança genética) e os modificáveis (estilo de vida, alimentação) e o processo de trabalho.

Além da educação em saúde, a estimulação ao autocuidado e da participação ativa do paciente e o diagnóstico precoce contribuem para a prevenção e recuperação da saúde. Daí a importância da implementação de programas de educação em saúde (MARTINS A, et al., 2013)

\section{Desvelando o Papel do Enfermeiro em Frente à Assistência às Úlceras}

De acordo com dados demográficos do Brasil estima-se que nascem 3000 crianças por ano com doença falciforme, com prevalência nos estados de maior concentração de afrodescendentes, agrupados entre os mais pobres. A taxa de letalidade por ausência de cuidados é de $8 \%$ nas crianças até os 2 anos e $43 \%$ das gestantes evoluem mal (BRASIL, 2012).

A Política Nacional de Atenção Integral às Pessoas com Doença Falciforme e outras Hemoglobinopatias, foi instituída pela a portaria 1.391/05 visando à organização da rede de assistência do sistema único de saúde (SUS) às pessoas com doença falciforme onde é apresenta as seguintes diretrizes: promoção da garantia do seguimento das pessoas diagnosticadas com hemoglobinopatias pelo Programa Nacional de Triagem Neonatal (PNTN) (BRASIL, 2012).

A Política Nacional de Atenção Integral às Pessoas com Doença Falciforme tem como objetivo promover a mudança na história natural da doença no Brasil, após a implantação dessa política diversas melhorias foram identificadas na assistência para esses pacientes como: redução do tempo de espera para consulta, medicações e materiais adequados, capacitação das equipes de saúde. O Instituto Estadual de Hematologia é situado no Rio de Janeiro sendo considerado o centro de referência nacional especializado no atendimento a pacientes com hemoglobinopatias hereditárias. Se faz necessário as adoções de medidas educativas a fim de reduzir o surgimento de úlceras de perna (MARTINS A, et al., 2014).

É importante que essa política seja adotada em todo o Brasil e que os profissionais estejam devidamente treinados para assistir esses pacientes, pois segundo os estudos é essencial uma equipe multiprofissional para discutir o quadro do paciente. Nessa perspectiva ações relacionadas a educação permanente e continuada visando a capacitação profissional, os treinamentos devem ser em conjunto com as equipes do setor (BRASIL, 2012; MARTINS A, et al., 2013)

O profissional de enfermagem tem papel fundamental no que diz respeito ao cuidado e tratamento de feridas por estar diretamente relacionado a este tipo de serviço, seja na atenção primária, secundária ou terciária. Este profissional é capaz de proporcionar um cuidado de forma holística ao acompanhar a evolução da lesão, orientar e executar o curativo de forma eficiente e humanizada ao mesmo passo em que observa os fatores de risco locais, sistêmicos, psicossociais e externos que condicionem o surgimento ou interfiram no processo de cicatrização da ferida como, por exemplo, comorbidades, medicamentos utilizados, sinais flogisticos e aspectos nutricionais (JUNQUEIRA PC, et al., 2009; MARTINS A, 2013; SILVA RCL, 2007). 
Martins A, et al. (2014) acrescentam também que, para uma atuação satisfatória do enfermeiro na assistência a pacientes com úlceras venosas, além do conhecimento técnico científico, este profissional necessita da utilização de instrumentos no seu cotidiano de trabalho como, por exemplo, as escalas. $O$ atendimento de enfermagem deve ser cuidadoso e regular, juntamente com a orientação e a educação da pessoa que são importantes à progressão do processo cicatricial ao longo do tratamento.

É possível identificar com o levantamento deste estudo que, com um bom conhecimento sobre as formas de diagnosticar e tratar a úlcera de perna falciforme, além do esforço e do trabalho especializado de todos os profissionais envolvidos, bem como o conhecimento expandido das novas possibilidades terapêuticas por meio do enorme arsenal de produtos para curativos disponíveis, incluindo a nova biotecnologia de produtos neles baseados, torna-se possível superar ou pelo menos controlar o peso desta enfermidade aos pacientes e seus familiares. É possível também, conhecendo-se os fatores de risco, aplicálos aos pacientes sem úlcera, mas com potencial para desenvolvê-la, e desencadear medidas preventivas. Nesta perspectiva, houve alguns consensos nas pesquisas analisadas sobre a abordagem e a condução desses casos (PALADINO SF, 2007; NAOUM FA, 2010).

$\mathrm{Na}$ literatura foi apontado a importância do profissional responsável pela assistência em realizar uma abordagem racional, reconhecendo detalhadamente o quadro clínico, a patogenicidade, as possibilidades de diagnóstico e o tratamento das causas comuns. Houve consensos também de que os métodos tradicionais na condução dos casos como higiene local, elevação das pernas e repouso auxiliam um bom prognóstico, bem como os curativos em gel, antibióticos tópicos, a suplementação com zinco, os enxertos de pele, desbridamento, o uso da arginina butirato e a contraindicação da bota de Unna (MARTINS A, 2013).

\section{CONSIDERAÇÕES FINAIS}

Durante o estudo percebeu-se que os requisitos necessários para a implantação/construção de uma unidade de tratamento de feridas são poucos e de fácil execução quando comparados com os benefícios que uma unidade deste tipo pode oferecer aos seus pacientes. Foi possível identificar com o levantamento deste estudo que, os profissionais responsáveis pela assistência devem ter conhecimento da ampla variedade de possibilidades terapêuticas que podem auxiliá-los na condução dos casos de úlcera de perna falciforme e, que o esforço e o trabalho especializado de todos os profissionais envolvidos na assistência podem proporcionar um processo de cicatrização mais rápido e eficiente quando realizado de forma consensual. Sendo assim, cabe aos enfermeiros intervir de forma consensual na escolha adequada do tratamento.

\section{REFERÊNCIAS}

1. ARAÚJO PIC. O autocuidado na doenca falciforme. Rev. Bras. Hematol. Hemoter, 2007; 29(3): 239-246.

2. BRASIL. Ministério da Saúde. Secretaria de Atenção à Saúde. Manual de Eventos agudos em doença falciforme. DF: MS, 2005.

3. BRASIL. Ministério da Saúde. Secretaria de Atenção à Saúde. Departamento de atenção especializada. Doença falciforme. Úlceras: prevenção e tratamento. Brasília: Ministério da Saúde, 2012.

4. CAVALCANTE JM, MAIO MC. Entre negros e miscigenados: a anemia e o traço falciforme no Brasil nas décadas de 1930 e 1940. Hist. cienc. saude-Manguinhos, Rio de Janeiro, 2011; 18(2): 377-406.

5. DIAS ALAA. (Re) Construção do caminhar: itinerário terapêutico de pessoas com doença falciforme com histórico de úlcera de perna. Dissertação (Mestrado em saúde coletiva) - Universidade Federal da Bahia, Salvador, 2013: 190p.

6. DUMVILLE JC, et al. Larval therapy for leg ulcers (VenUS II): randomized controlled trial. BMJ, 2009; 33(2):338-45.

7. FERNANDES AP, et al. Cuidado de úlceras falciformes em crianças. J Pediatr., Rio de Janeiro, 2010; 86(9): 279-84.

8. HALABI TM, et al. Sickle cell leg ulcers: a frequently disabling complication and a marker of severity. $\mathrm{Br} \mathrm{J}$ Dermatol,2008; 158(2): 339-44.

9. JUNQUEIRA PC, et al. Hemoterapia Clínica. São Paulo: Roca Ltda. 2009.

10. KIKUCHI BA. Assistência de enfermagem na doença falciforme nos serviços de atenção básica. Rev. bras. hematol. Hemoter, 2007; 29(3): 331-338. 
11. LOBO C, et al. Crises Dolorosas na Doença Falciforme. Rev. Bras. Hematol. Hemoter,2007: 29(3): 247-258.

12. MARTINS, A. et al. O autocuidado para o tratamento de úlcera de perna falciforme: orientações de enfermagem. Esc. Anna Nery,2013; 17(4): 755-763.

13. MARTINS A, et al. Cuidado de enfermagem ao cliente com úlcera crônica de perna secundária à anemia falciforme. Rev. Enf. Profissional, 2014; 1(1): 61-71.

14. NAOUMFA. Managing leg ulcer pain in sickle cell disease. Rev. Bras. Hematol, 2010; 32(2).

15. NEVES AF, et al. Avaliação da analgesia de opióides tópico em úlcera de perna de pacientefalcêmico. Rev. Bras. Hematol. Hemoter., São José do Rio Preto, set 2010; 32 (2).

16. NOLAN VG, et al. Sickle cell leg ulcers: associations with haemolysis and SNPs in Klotho, TEK and genes of the TGF-beta/BMP pathway. Br J Haematol. 2006; 133(5): 570-78.

17. PALADINO SF. Úlcera de membros inferiores na anemia falciforme. Rev. bras. Hematol,2007; 29(3): $288-290$.

18. RAMALHO AS, MAGNA LA. Aconselhamento genético do paciente com doença falciforme - Rev. Bras. Hematol. Hemoter., São José do Rio Preto, 2007; 29(3): 12-21.

19. SILVA RCL, et al. Feridas: fundamentos e atualizações em enfermagem. São Caetano do Sul: Yendis; 2007.

20. SPIRA JAO, et al. Estimated costs in treating sickle cell disease leg ulcer. Revista da Escola de Enfermagem da USP. 2020; 54 (e03582).

21. TRENT JT. Leg ulcers in sickle cell disease. Adv Skin Wound Care,2004; 17(3): 410-16.

22. VERÍSSIMO MPA. Crescimento e desenvolvimento nas doenças falciformes. Rev. Bras. Hematol,2007; 29(3): 271 274. 